\title{
A community based walk-in clinic for mentally handicapped adults - is there a need?
}

\author{
Jay Nadarajah, Senior Registrar in Developmental Psychiatry, Chelmsley Hospital, \\ Marston Green, Birmingham B37 7HL; and KATE Gingell, Registrar, Worcester \\ Royal Infirmary, Newtown Road Branch, Worcester
}

Mentally handicapped people have the same rights in terms of good quality and range of care as other members of society. This has been highlighted by the recent emphasis on community care for psychiatric patients irrespective of their disability.

Recently attention has focused on the utility of walk-in or emergency clinics in defusing crises and allowing prompt and adequate treatment for the mentally ill. These clinics vary in their method of functioning and the population served. Some, such as the Maudsley Emergency Clinic (Lim, 1983), offered a 24-hour service to anyone regardless of catchment area, some of no fixed abode and the majority coming from other areas of London other than its catchment area! Kehoe \& Newton (1990) describe a 24-hour service which has medical staff assigned to it during the day but served by duty registrars at night and confined to the catchment area. Psychiatric emergency clinics are generally felt to serve a useful purpose, although there may be problems in terms of logistics of time and space and aftercare provision (Smithies, 1986). A large proportion were self-referrals, although a higher proportion of general practitioner referrals were generally admitted (Haw et al, 1987).

It is clear that a walk-in clinic for the mentally handicapped is likely to receive few self-referrals and referrals would be made by a member of the family or multidisciplinary team caring for an individual. This is not to deny the possibility that a walk-in clinic might serve a useful purpose for this client group. We describe our experience of setting up a walk-in clinic for persons with mental handicap in an adult training centre.

\section{The study}

In early 1990 a walk-in clinic was set up in an adult training centre (ATC) in Shropshire. The ATC is used by 166 people and it provides a variety of comprehensive programmes for their clients. Twelve of the clients require special care but the majority have moderate or mild learning disabilities. Most live with their families in and around Telford but some come from the surrounding rural areas. Many are known to the mental handicap psychiatric services but a substantial number are not. The walk-in clinic was held on one morning a week and all clients were seen by a senior registrar and a registrar. The request for a client to be seen could be made by any member of the ATC staff, the social worker, psychologist or family. If possible, doctors were informed beforehand so that they could obtain casenotes, if available, prior to the consultation. If parents were unable to attend, they were sometimes visited at home to discuss the problems and further management of their relative.

\section{Findings}

Over a period of five months (March to July 1990), excluding holiday breaks at the ATC, 16 clinics were held. Thirty-four consultations were made for a total of 12 clients. (The mean number of consultations per client was three with a range of one to seven). The following two vignettes give examples of the nature of problems presented.

Miss A is a 35-year-old woman with mild mental handicap who lives with her elderly mother and a younger brother who has congenital cataracts and epilepsy. She was admitted to hospital with the first episode of affective disorder with hypomanic features but mother took her home against medical advice after a few days. Mrs A could not cope with her daughter's illness since she would get up in the middle of the night to get dressed to go to the Post Office or to do her laundry. However, she adamantly refused Miss A's readmission to hospital. Since Miss A was a regular attender of the ATC where the clinic was held, her mother found it more acceptable to bring her for further examinations there. Miss A's mental state was gradually stabilised on neuroleptics which were later slowly reduced and stopped. Miss A continues to attend the ATC and is seeking outside employment.

Ms C is a 40-year-old, mildly handicapped woman who lives in a hostel. She was brought in by the social worker due to her behavioural problems, which had culminated in her trying to smother another resident at the hostel. After detailed assessment, no psychiatric illness was diagnosed and she was considered to have a personality disorder. She was seen on six occasions for brief individual counselling. The sessions focused on problem-solving techniques aimed at reducing her impulsivity. At present she is managing to remain in control of herself. 
Six months after the initiation of the clinic it was decided to find out whether the clinic provided a useful service in order to assess the need for continued provision. A short questionnaire was devised for the staff of the ATC, the psychologist and the social worker to complete. Questions were mainly aimed at finding out whether staff felt the timing and location of the clinic was useful and whether they felt that clients benefited from being seen in familiar surroundings in a flexible and informal manner. They were asked if the suggested management and treatment was found useful and if there had been any effect on communication between carers. Some of the questions focused on the perceived need for further teaching and the necessity for extending the service to provide support groups for families of any client of the ATC.

Out of 21 questionnaires, 19 were completed and returned. The majority of staff (17) $(89.5 \%)$ felt that having a walk-in clinic as described had been very helpful and they found it easier to refer clients with problems which would not otherwise have come to medical attention. Two of the staff $(10.5 \%)$ stated that, although they found the clinic useful, they felt that it would have been better if it had been held somewhere else. There was a unanimous response in favour of further teaching and a 'drop-in' system for parents.

\section{Comment}

The majority of people seen in the general psychiatric walk-in clinics are self-referred $(1-4)$ or referred by GPs. In contrast, our client group generally lacks enough insight to realise the need for consultation. Indeed our only self-referral was from a client requesting dental treatment! Therefore one has to rely on the observation of carers and their motivation to seek help for the clients for whom they are responsible. Providing this kind of clinic will facilitate such referrals who would not otherwise have come to medical attention so promptly, if at all.
Although an out-patient clinic might serve a similar function, we believe that a walk-in clinic differs from it in important ways and the two are not mutually exclusive. A walk-in clinic should be easily accessible not only to the clients but also to the carers. Thus our choice of an ATC is only one of several possible venues. It is possible that holding the clinic in a work-orientated place such as an ATC has precluded the typical presentation more common to walk-in clinics in general psychiatry such as alcoholrelated and social problems.

Interesting, challenging problems were encountered with a wide variety of solutions and an educational purpose served. Communication and therefore management was felt to be improved between all carers and it has been decided to continue to hold the clinic.

To our knowledge, this is the only description of a walk-in clinic catering for this client group. We would be interested to learn of similar experiences which may enable us to improve our service since it is clear that more research is needed in this area.

\section{Acknowledgement}

We would like to thank staff at Halesfield Centre for their co-operation in completing the questionnaire.

\section{References}

Haw, C., Lanceley, C. \& Vickers, S. (1987) Patients at a psychiatric walk-in clinic-Who, how, why and when? Bulletin of the Royal College of Psychiatrists, 11, 329-332.

KeHOE, R. F. \& NEWTON, R. (1990) Do patients need a psychiatric emergency clinic? Bulletin of the Royal College of Psychiatrists, 14, 470-472.

Lm, M. H. (1983) A psychiatric emergency clinic: a study of attendances over 6 months. British Journal of Psychiatry, 143, 460-466.

Smtrues, J. M. A. (1986) A psychiatric emergency clinic. Bulletin of the Royal College of Psychiatrists, 10, 357-359. 